\title{
КАЛЛУСООБРАЗОВАНИЕ В КУЛЬТУРЕ ПЫЛЬНИКОВ МОМОРДИКИ (Momordica charantia L.) В ЗАВИСИМОСТИ ОТ СТАДИИ РАЗВИТИЯ МИКРОСПОР И СОСТАВА ПИТАТЕЛЬНОЙ СРЕДЫ
}

\author{
М.Л. НГУЕН1, Ч.Х.Т. ТА'1, Т.Н.В.Т. ХУЕН1, А.В. ВОРОНИНА
}

Культура пыльников - один из эффективных методов создания чистых линий за короткое время. С его помощью можно ускорить процесс получения $\mathrm{F}_{1}$ гибридов момордики (Momordica charantia L., сем. Cucurbitaceae) - экономически важной сельскохозяйственной культуры, которую возделывают в тропических и субтропических странах Южной Америки, Азии и Африки. Достаточно эффективная технология культивирования пыльников момордики пока что не разработана. В настоящем исследовании мы показали, что размер бутонов достоверно $(p \leq 0,05)$ влияет на способность формирования каллусов момордики. Выявлено, что частота каллусообразования, морфология каллусов и время начала их формирования в культуре пыльников in vitro существенно зависят от состава и концентрации регуляторов роста в питательной среде. Кроме того, впервые исследована динамика каллусообразования в процессе культирования пыльников момордики. Целью работы было изучение влияния стадии развития микроспор и состава питательных среды на способность каллусообразования в культуре пыльников in vitro. В качестве материала использовали растения $F_{1}$ гибрида момордики Diago 26. Растения выращивали в 2018 году в открытом грунте (уезд Дайлок, провинция Куангнам, Вьетнам) по общепринятой методике для получения товарных плодов. Бутоны отбирали в утренние часы $\left(5^{00}-7^{00}\right)$ и хранили в полиэтиленовых пакетах при $4{ }^{\circ} \mathrm{C}$ в течение 1 сут. Бутоны поверхностно стерилизовали $70 \%$ спиртом и $5 \%$ раствором гипохлорита натрия $(\mathrm{NaOCl})$. Пыльники извлекали из бутонов и помещали на питательные среды в чашки Петри. Культивирование осуществляли при температуре $25 \pm 2{ }^{\circ} \mathrm{C}$ с фотопериодом 16 ч день/8 ч ночь в течение 4 нед. Использовали три варианта питательной среды Мурасиге-Скуга, различающихся по составу и концентрации регуляторов роста: МК1 с добавлением 1,0 мг/л 2,4-Д (2,4-дихлорфеноксиуксусная кислота) и 1,5 мг/л БАП (6-бензиламинопурин); МК2 - 1,5 мг/л 2,4-Д и 1,0 мг/л БАП; МК3 - 1,5 мг/л НУК (1-нафталинуксусная кислота), 1,0 мг/л БАП и 0,5 мг/л кинетина. Статистическую обработку полученных данных проводили в программах IBM SPSS Statistics 22 и Microsoft Excel 2013. Выявлено, что в одном пыльнике содержались микроспоры на разных стадиях развития, поэтому ввести в культуру материал с микроспорами на одной определенной стадии невозможно. Однако можно выявить одну стадию развития, которая численно преобладает. Мы культивировали пыльники из бутонов, разделенных на две группы: бутоны длиной 4,0-5,0 мм, которые содержали ранние и средние одноядерные микроспоры, и бутоны длиной 5,1-6,5 мм, в которых находились поздние одноядерные и двуядерные микроспоры. При культивировании пыльников из бутонов длиной 4,0-5,0 мм каллусы формировались в течение 1 нед после введения в культуру, из бутонов размером 5,1-6,5 мм - в течение 2-й нед. Самую высокую частоту формирования каллусов $(93,75 \pm 2,55 \%)$ наблюдали при использовании питательной среды MS с добавлением 1,0 мг/л 2,4-Д и 1,5 мг/л БАП (МК1). Большая часть каллусов формировались на 2-й и 3-й нед культивирования. Также наблюдали существенное различие в морфологии каллусов, полученных на трех питательных средах разного состава. Каллусы на среде МК1 имели желтый цвет, очень плотную консистенцию, на МК2 зеленый цвет и также очень плотную консистенцию, на МК3 - зелено-желтый цвет и консистенцию средней плотности. При этом мы не выявили влияния стадии развития микроспор на морфологию каллусов. Несмотря на значительное количество полученных каллусов, образование эмбриоидов мы не наблюдали.

Ключевые слова: Momordica charantia L., момордика, каллусообразование, удвоенные гаплоиды, культура пыльников.

Момордика (Momordica charantia L., сем. Cucurbitaceae) - экономически значимая сельскохозяйственная культура, которую возделывают в тропических и субтропических странах Южной Америки, Азии и Африки $(1,2)$. В странах Азии момордику можно выращивать в течение всего года (3). Площадь, занимаемая этой культурой, составляет около 340 тыс. га, при этом большая часть производства сосредоточена в Китае и Индии (4).

* Исследование финансируется Фондами развития науки и технологии Университета Дананг по номеру проекта B2017-DN03-13. 
Плоды момордики используют не только в кулинарии, но и в медицине при лечении различных болезней - диабета, подагры, рака $(5,6)$. Химический анализ показал, что момордика содержит сапонины (момордисин, момордин), которые обладают антибактериальным, антигрибным, антивирусным, инсектицидным эффектом (7).

В настоящее время около $80 \%$ семян момордики, используемых в производстве, - гибридные (8). Однако ассортимент гибридов этой культуры остается ограниченным из-за сложности и длительности селекционного процесса. Современная селекция $\mathrm{F}_{1}$ гибридов в основном зависит от наличия инбредных линий, при этом именно их создание отличается сложностью (9). Для получения инбредных линий традиционными методами селекции необходимо проводить самоопыления в течение 5-7 поколений $(10,11)$. Для ускорения селекционного процесса можно применять технологии создания удвоенных гаплоидов (doubled haploid, DH) $(12,13)$. DH растения были получены более чем у 200 видов, эта технология широко применяется на капустных и зерновых культурах $(14,15)$. Одним из первых и популярных методов создания DH было культивирование пыльников. Для получения удвоенных гаплоидов у ряда культур этот метод остается единственным. Успех технологии зависит от многих факторов, таких как генотип, стадия развития микроспор, состав питательной среды, использование регуляторов роста, физические условия культивирования, способность регенерации растений из каллуса (16). В связи с этим DHтехнологию необходимо оптимизировать для конкретной культуры и даже генотипа. Особенно это актуально для овощных культур (17).

Ряд исследователей, проводивших работу по культивированию пыльников момордики, получили каллусы, однако не смогли добиться регенерации из них растений (18-20). Ү. Tang с соавт. (19) установили, что каллусы успешно образовывались после предобработки бутонов низкой положительной температурой $4{ }^{\circ} \mathrm{C}$ в течение 48 ч на среде Мурасиге-Скуга (MS) с добавлением 3 \% сахарозы, 0,5 мг/л 2,4-Д (2,4-дихлорфеноксиуксусная кислота) и 2,0 мг/л БАП (6-бензиламинопурин). Добавление витамина $\mathrm{C}$ и $\mathrm{AgNO}_{3}$ способствует снижению частоты некротизирующих каллусов (19).

На сегодняшний день опубликовано очень небольшое количество работ, описывающих каллусообразование в культуре пыльников момордики, до сих пор нет однозначного мнения о действии ряда факторов.

В представляемом исследовании мы показали, что размер бутонов, то есть стадия развития микроспор, достоверно $(\mathrm{p} \leq 0,05)$ влияет на способность формирования каллусов момордики. При этом в одном пыльнике могут содержаться микроспоры на разных стадиях развитий. Выявлено, что частота каллусообразования, морфология каллусов и время начала их формирования в культуре пыльников in vitro существенно зависят от состава и концентрации регуляторов роста в питательной среде. Кроме того, впервые исследована динамика каллусообразования в процессе культирования пыльников момордики.

Целью работы было изучение влияния стадии развития микроспор и состава питательных среды на способность каллусообразования в культуре пыльников in vitro.

Методика. В качестве материала использовали растения $\mathrm{F}_{1}$ гибрида момордики Diago 26 (производитель семян «Công ty trách nhiệm hữu hạn LLC», Вьетнам). Растения выращивали в 2018 году в открытом грунте (уезд Дайлок, провинция Куангнам, Вьетнам) по общепринятой методике для получения товарных плодов. Бутоны отбирали в утренние часы $\left(5^{00}-7^{00}\right)$ и 
хранили в полиэтиленовых пакетах при $4^{\circ} \mathrm{C}$ в течение 1 сут для холодовой предобработки.

Стадию развития микроспор контролировали микроскопированием с использованием красителя ацетокармина (21). Микроспоры с помощью препаровальных игл выделяли из бутонов в каплю глицерина на предметное стекло. Микрокапиллярной трубкой переносили микроспоры на новое предметное стекло с каплей 2 \% раствора ацетокармина, накрывали покровным стеклом и просматривали при увеличении $\times 400$ (микроскоп Ахіо Imager.M2, «Carl Zeiss», Германия). Стадию развития определяли по числу ядер и их расположению в клетке (22). Чтобы оценить связь между размером бутонов и стадией развития микроспор, изучали бутоны размером от 4,0 до 7,0 см с интервалом 0,1 см. В каждом размерном интервале отбирали по 450 микроспор из трех пыльников.

Отобранный растительный материал вводили в культуру in vitro. Бутоны в течение 30 с промывали 70 \% спиртом, затем дважды по 15 с стерильной дистиллированной воде, далее погружали в $5 \%$ раствор гипохлорита натрия $(\mathrm{NaOCl})$ на 4 мин, после чего 5 раз по 15 с промывали в стерильной дистиллированной воде. С помощью пинцета извлекали пыльники, стараясь удалять тычиночные нити. Пыльники помещали на твердую питательную среду в пластиковые чашки Петри диаметром 6 см (по 8 пыльников на чашку). Введенные в культуру пыльники инкубировали при температуре $25 \pm 2{ }^{\circ} \mathrm{C}$ с фотопериодом 16 ч день/8 ч ночь.

В опыте использовали три варианта питательных сред: MK1, MK2, MK3. Среды были составлены на основе базовой среды MS, содержащей $3 \%$ сахарозы и $0,7 \%$ агара $(\mathrm{pH} 5,8)$ с добавлением регуляторов роста: 1,0 мг/л 2,4-Д и 1,5 мг/л БАП для МК1; 1,5 мг/л 2,4-Д и 1,0 мг/л БАП для МК2; 31,5 мг/л НУК (1-нафталинуксусная кислота), 1,0 мг/л БАП и 0,5 мг/л кинетина (K) для МК3. Питательные среды автоклавировали при $121{ }^{\circ} \mathrm{C}, 1$ атм. в течение 20 мин и разливали по чашкам Петри.

Эффективность каллусообразования оценивали по соотношению числа образовавшихся каллусов и культивируемых пыльников, а также по окраске и плотности каллусов. Опыты проводили в 4 повторностях, количество пыльников в каждой повторности составляло 24 шт.

Результаты обрабатывали статистически в программе IBM SPSS Statistics 22 («IBM Corporation», США). Определяли средние значения изучаемых показателей $(M)$, стандартные ошибки среднего ( \pm SEM) и доверительный интервал при $95 \%$ доверительной вероятности $\left(t_{0,05} \times \mathrm{SEM}\right)$. Достоверность различий между вариантами оценивали с использованием параметрического критерия ( $t$-критерий Стьюдента). Различия между вариантами считали статистически значимыми при $\mathrm{p} \leq 0,05$. Графики были построены в программе Microsoft Excel 2013.

Результаты. Известно, что стадия развития микроспор - критический фактор, который определяет успех технологии культуры пыльников (23). Каждая стадия соответствует определенному интервалу размеров бутонов (24), поэтому мы исследовали соотношения между размерами бутонов и стадиями развития микроспор у гибрида Diago 26, что служило основанием для отбора подходящих бутонов для дальнейшего культивирования.

Как было показано, в одном пыльнике могли одновременно присутствовать микроспоры на разных стадиях развития, начиная с ранней одноядерной и до двуядерной (рис. 1). Отобрать бутоны момордики с микроспорами, находящимися на одной стадии развития, не представлялось возможным. Кроме того, в зависимости от размера бутона соотношение количества микроспор, находящихся на разных стадиях развития, раз- 
личалось. В бутонах одного размера это соотношение было аналогичным. При этом одна стадия всегда численно преобладала (рис. 2).

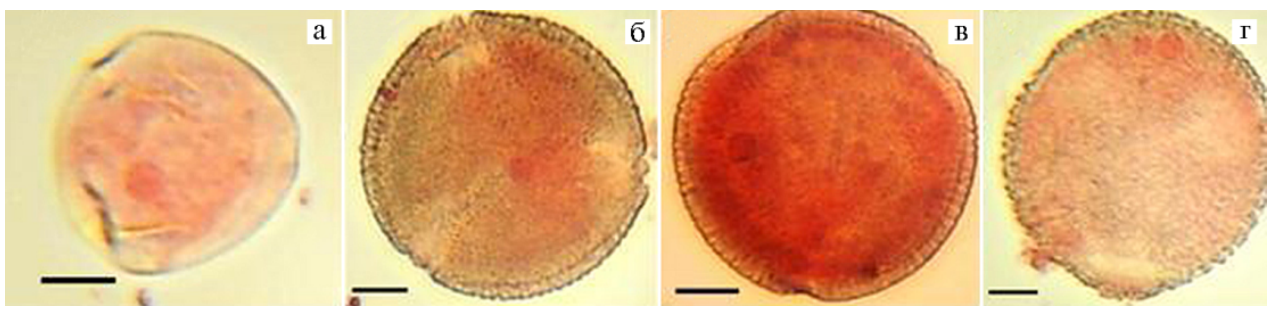

Рис. 1. Стадии развития микроспор $F_{1}$ гибрида момордики (Momordica charantia L.) copта Diago 26: a - ранняя одноядерная, б - средняя одноядерная, в - поздняя одноядерная, г двуядерная. Масштабная линейка 10 мкм (микроскоп Axio Imager.M2, «Carl Zeiss», Германия, увеличение $\times 400)$.

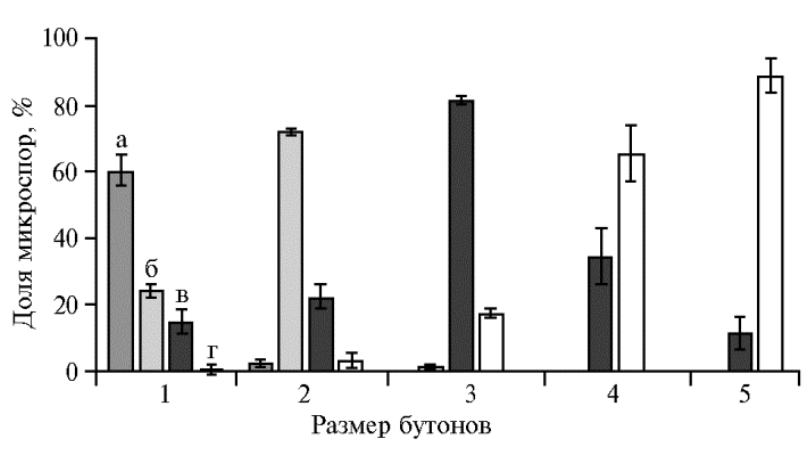

Рис. 2. Доля микроспор $\mathrm{F}_{1}$ гибрида момордики (Momordica charantia L.) Diago 26 на ранней одноядерной (a), средней одноядерной (б), поздней одноядерной (в) и двуядерной (г) стадиях развития в бутонах разного размера: $1-4,0-4,5$ мм, $2-4,6-5,0$ мм, 3 - 5,1-6,0 мм, $4-6,0-6,5$ мм, $5-6,6-$ 7,0 мм.

В результате цитологического анализа препаратов пыльников было выявлено, что в бутонах длиной 4,0-4,5 мм одновременно присутствовали микроспоры на четырех стадиях развития. Преобладали ранние одноядерные микроспоры, составляя $60,19 \pm 2,32 \%$, средних одноядерных содержалось 24,08土0,98 \%, доля поздних одноядерных равнялась $14,99 \pm 1,8 \%$, дву-

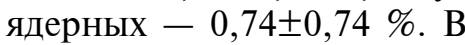
бутонах длиной 4,6-5,0 мм также были обнаружены четыре стадии развития микроспор с преобладанием средних одноядерных $(71,98 \pm 0,42 \%)$. Следовательно, хотя и невозможно выделить пыльники с одной стадией развития микроспор, можно отобрать бутоны, в пыльниках которых оптимальная стадия преобладает. В пыльниках бутонов размером 5,1-6,0 мм мы обнаружили микроспоры только двух стадий развития (поздняя одноядерная и двуядерная) при большей доле поздние одноядерные микроспоры $(82,64 \pm 0,59 \%)$. В бутонах

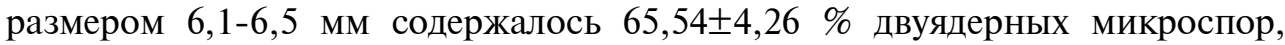

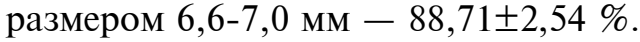

Полученные в настоящей работе результаты отличаются от ранее опубликованных данных. Y. Tang с соавт. (18) установили, что один интервал размера бутонов соответствует только одной стадии развития микроспор: бутоны длиной 3,0-4,0 мм содержали ранние одноядерные микроспоры, в бутонах 4,0-5,0 мм находились поздние одноядерные микроспоры, в бутонах размером > 5,0 мм - двуядерные микроспоры. Это отличие может быть обусловлено тем, что связь между размером бутонов и стадией развития микроспор зависит от генотипа. Такое заключение было сделано и для ряда других культур (25). Следовательно, для достижения лучшего результата в культуре пыльников необходимо определять связь между размером бутонов и стадией развития микроспор для каждого генотипа.

Для изучения влияния стадии развития микроспор на эффективность каллусогенеза мы вводили в культуру пыльники бутонов двух следующих размеров: 4,0-5,0 мм, содержащие ранние одноядерные и средние 
одноядерные микроспоры; 5,1-6,5 мм, содержащие поздние одноядерные и двуядерные микроспоры. Две группы пыльников культивировали на трех вариантах питательных сред MK1, MK2, MK3, различающихся концентрацией и составом регуляторов роста. Добавление регуляторов роста и размер бутонов достоверно $(\mathrm{p} \leq 0,05)$ влияли на эффективность каллусогенеза в культуре пыльников момордики, при этом отсутствовало взаимодействие между двумя этими факторами. Полученный результат согласуется с данными публикаций, описывающих культивирование пыльников момордики и других культур $(18,26,27)$. Введение в культуру материала, представленного ранними и средними одноядерными микроспорами, приводило к более высокой частоте образования каллусов. Средняя частота каллусогенеза

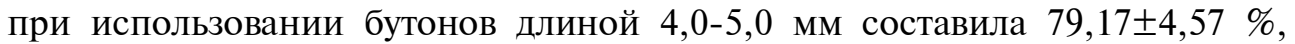

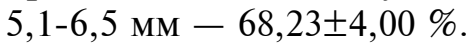

Наиболее эффективным оказалось использование питательной среды MK1 и бутонов размером 4,0-5,0 мм (табл.). В этом варианте частота

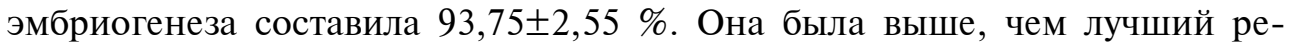
зультат (80,55 \%), представленный в публикации Ү. Tang с соавт. (19), которые культивировали пыльники на среде MS с добавлением 0,5 мг/л 2,4-D и 2,0 мг/л БАП. Также выявлено существенное влияние на частоту формирования каллуса состава питательных сред MK1 и MK2, MK2 и MK3, независимо от размера бутонов. Однако между MK1 и МК3 достоверных различий не установлено. Самую низкую частоту образования кал-

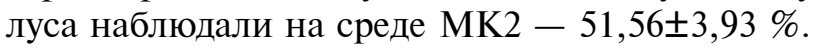

Каллусообразование в культуре пыльников момордики (Momordica charantia L.) $F_{1}$ гибрида Diago 26 в зависимости от размера бутонов и состава питательной среды $(M \pm \mathrm{SEM})$

\begin{tabular}{|c|c|c|c|c|c|c|c|}
\hline \multirow[t]{2}{*}{ Среда } & \multicolumn{4}{|c|}{$\begin{array}{l}\text { Концентрация регуляторов } \\
\text { роста, мг/л }\end{array}$} & \multicolumn{2}{|c|}{ Образование каллусов } & \multirow{2}{*}{$\begin{array}{l}\text { Морфология } \\
\text { каллусов }\end{array}$} \\
\hline & $2,4-Д$ & БАП & $\mathrm{K}$ & НУК & частота, \% & время начала & \\
\hline \multicolumn{8}{|c|}{ Раз мер бутонов $4,0-5,0$ мм } \\
\hline MK1 & 1,0 & 1,5 & - & - & $93,75 \pm 2,55^{\mathrm{a}}$ & 1-я нед & $\begin{array}{l}\text { Желтый цвет, очень } \\
\text { плотные }\end{array}$ \\
\hline MK2 & 1,5 & 1,0 & - & - & $60,94 \pm 5,33^{\text {be }}$ & 1-я нед & $\begin{array}{l}\text { Зеленый цвет, очень } \\
\text { плотные }\end{array}$ \\
\hline MK3 & - & 0,5 & 1,0 & 1,5 & $82,81 \pm 2,99^{a f}$ & 1-я нед & $\begin{array}{l}\text { Зелено-желтый цвет, } \\
\text { средней плотности }\end{array}$ \\
\hline MK1 & 1,0 & 1,5 & $\begin{array}{l}\mathrm{Pa} \\
-\end{array}$ & р бу т & $\begin{array}{l}\text { о в } 5,1-6,5 \mathrm{mp} \\
73,44 \pm 2,99 \mathrm{cbf}\end{array}$ & 2-я нед & $\begin{array}{l}\text { Желтый цвет, очень } \\
\text { плотные }\end{array}$ \\
\hline MK2 & 1,5 & 1,0 & - & - & $51,56 \pm 3,93^{\mathrm{de}}$ & 2-я нед & $\begin{array}{l}\text { Зеленый цвет, очень } \\
\text { плотные }\end{array}$ \\
\hline MK3 & - & 0,5 & 1,0 & 1,5 & $79,69 \pm 2,99^{a f}$ & 2-я нед & $\begin{array}{l}\text { Зелено-желтый цвет, } \\
\text { средней плотности }\end{array}$ \\
\hline
\end{tabular}

Следовательно, у гибрида момордики Diago 26 каллус может формироваться из пыльников, содержащих микроспоры на разных стадиях развития. При этом наиболее подходят для культуры ранняя и поздняя одноядерные стадии, хотя для DH-технологии капустных культур оптимальными считаются поздние одноядерные и ранние двуядерные микроспоры (28), а для огурца подходящими были средние и поздние одноядерные микроспоры $(29,30)$. Как показали в своем исследовании Y. Tang с соавт. (18), при использовании пыльников, содержащих микроспоры на поздней одноядерной стадии, каллус момордики образуется с большей частотой, чем при культивировании материала на стадии тетрад и ранней одноядерной. В настоящей работе мы не выявили влияния взаимодей- 
ствия факторов размера бутона и состава питательной среды на частоту формирования каллусов.

Время начала каллусообразования различалось в зависимости от преобладающей стадии развития микроспор. При использовании бутонов меньшего размера формирование каллуса отмечали уже в 1-ю нед культивирования. При культивировании пыльников из более крупных бутонов каллус формировался только на 2-й нед. Это важно учитывать при определении времени пересадки образовавшихся каллусов на свежие питательные среды для субкультивирования или регенерации, поскольку каллусы могут иметь разные размеры при культивировании на питательной среде одного состава.

Динамика формирования каллусов также различалась по неделям. На среде MK1 максимальное количество каллусов формировалось на 2-й и 3-й нед культивирования, данные различались при использовании пыльников бутонов разных размеров (рис. 3). На средах MK2 и МК3 наиболее высокую частоту формирования каллусов наблюдали на 2-й нед. Каллусы на изученных средах формировались неодновременно, что приводило к различиям в их размерах каллусов даже в одном пассаже одного бутона. Это может затруднять процесс регенерации у момордики.

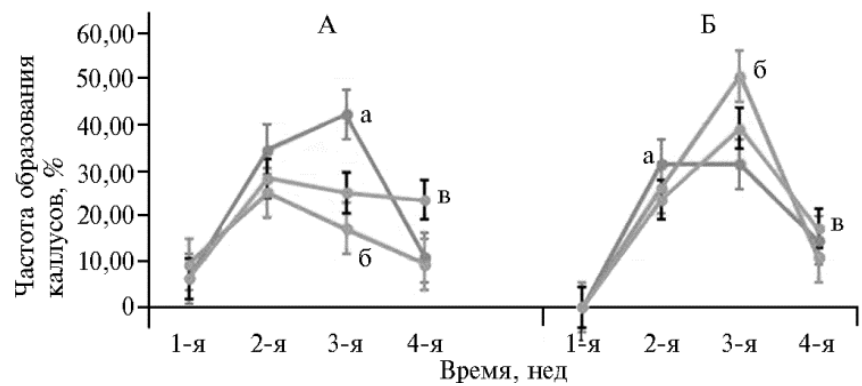

Рис. 3. Динамика формирования каллусов $\mathbf{F}_{1}$ гибрида момордики (Momordica charantia L.) Diago 26 при использовании микроспор из бутонов размером 4,0-5,0 мм (А) и $5,1-$ 6,5 мм (Б) на питательных средах MK1 (а), MK2 (б) и МК3 (в) в зависимости от времени культивирования. Описание сред см. в разделе «Методика».

Отмечались различия в морфологии каллусов, полученных на питательных средах с добавлением разных регуляторов роста через 4 нед после инокуляции. Каллусы, сформировавшиеся на питательной среде MK1, имели желтый цвет, очень плотную консистенцию, на МK2 - зеленый цвет и тоже очень плотную консистенцию, на МК3 - зелено-желтый цвет, консистенцию средней плотности (рис. 4). При этом мы не обнаружили влияния стадии развития микроспор на морфологию каллусов.

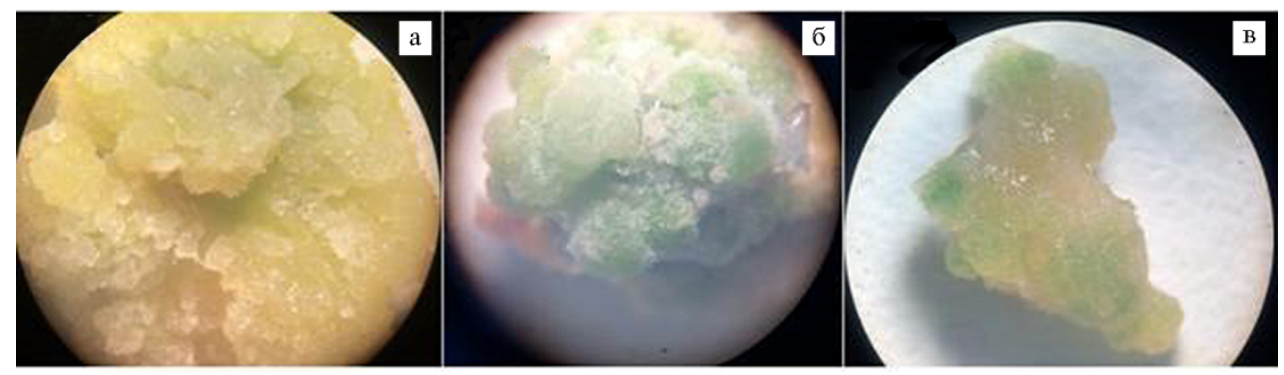

Рис. 4. Морфология каллусов $\mathrm{F}_{1}$ гибрида момордики (Momordica charantia L.) Diago 26 на питательных средах MK1 (а), MK2 (б), MK3 (в) после 4 нед культивирования. Описание сред см. в разделе «Методика» (микроскоп Axio Imager.M2, «Carl Zeiss», Германия, увеличение ×40).

В раннее опубликованных работах исследователи не анализировали время начала и динамику формирования каллусов. Есть сообщения только об общем времени их образования. Однако сроки формирования каллусов, обладающих способностью к регенирации, могут варировать в зависимости от генотипа и состава питательной среды. Например, у огурца жел- 
то-полупрозрачный эмбриогенный каллус образуется через 6 нед после индукции на питательной среде $(12,31)$. Для банана этот срок может продлиться до 4 мес (32).

Несмотря на высокую частоту каллусообразования на всех трех изученных питательных средах, ни одного эмбриоида мы не получили. Если каллусы культивировали на питательных средах дольше 4 нед, то они постепено некротизировались. Аналогичный результат получили Y. Tang c соавт. (20). Возможно, в клетках каллуса момордики накапливаются вторичные метаболиты, которые препятствуют образованию эмбриоидов и органогенезу. При сравнении соотношения концентрации эндогенных регуляторов роста (гибберелловая кисота $\mathrm{GA}_{3}$, зеатин, индол-3-уксуснвя кислота IAA, абсцизовая кислота АВА) в каллусах Y. Tang с соавт. (20) установили, что концентрация зеатина выше в каллусах, сформировавшихся из тканей стебля, чем из пыльников. При этом регенерация побегов наблюдалась только у каллусов, полученных из тканей стебля. Кроме того, у каллусов, способных к регенерации, были ниже значения соотношений IAA/зеатин и $\mathrm{GA}_{3} /$ зеатин (20).

Таким образом, выявлено существенное влияние концентрации и типа регуляторов роста на скорость и частоту формирования каллусов, а также их морфологию в культуре пыльников момордики (Momordica charantia) $\mathrm{F}_{1}$ гибрида Diago 26. Установлено, что в одном пыльнике могут содержаться микроспоры на разных стадиях развития. Также выявлено существенное различие по способности к каллусогенезу между пыльниками с ранними средними одноядерными и поздними одноядерными двуядерными микроспорами. Для получения наибольшей частоты формирования каллуса, составившей 93,75 \%, необходимо культивировать пыльники из бутонов длиной 4,0-5,0 мм на среде MS, содержащей $3 \%$ сахарозы и 0,7 \% агара с добавлением 1,0 мг/л 2,4-дихлорфеноксиуксусной кислоты и 1,5 мг/л 6-бензиламинопурин.

\footnotetext{
1University of Education - The University of Da Nang, Поступила в редакцию Vietnam, Danang city, 459 - Ton Duc Thang st.,

e-mail:nmly@ued.udn.vn $\varangle$, tienhuentonnubao@gmail.com, 4 ноября 2018 года
} thaotth88@gmail.com;

${ }^{2}$ ФББОУ ВПО Российский государственный аграрный университет-МСХА им. К.А. Тимирязева, 127550 Россия, г. Москва, ул. Тимирязевская, 49,

e-mail: chistovan@mail.ru

\section{ANTHER-DERIVED CALLUS FORMATION IN BITTER MELON (Momordica charantia L.) AS INFLUENCED BY MICROSPORE DEVELOPMENT STAGE AND MEDIUM COMPOSITION}

\section{M.L. Nguyen ${ }^{1}$, T.H.T. Ta ${ }^{1}$, T.N.B.T. Huyen ${ }^{1}$, A.V. Voronina ${ }^{2}$}

\footnotetext{
${ }^{1}$ University of Education - The University of Da Nang, Vietnam, Danang city, 459 - Ton Duc Thang st., e-mail nmly@ued.udn.vn( $₫$ corresponding author), tienhuyentonnubao@gmail.com, thaotth88@gmail.com;

${ }^{2}$ Timiryazev Russian State Agrarian University-Moscow Agrarian Academy, 49, ul. Timiryazevskaya, Moscow, 127550 Russia, e-mail chistovan@mail.ru ORCID:

Nguyen M.L. orcid.org/0000-0002-0652-891X

Ta T.H.T. orcid.org/0000-0002-0652-4601

The authors declare no conflict of interests

Acknowledgements:

Funded by Da Nang University Science and Technology Development Foundation by project No. B2017-DN03-13

Received November 4, 2018

Huyen T.N.B.T. orcid.org/0000-0003-0467-9391 Voronina A.V. orcid.org/0000-0003-0249-246X doi: 10.15389/agrobiology.2019.1.140eng
}

Abstract 
This method can be applied to accelerate the breeding process of $\mathrm{F}_{1}$ hybrids of bitter melon (Momordica charantia L., family Cucurbitaceae), which is an important commercial crop in tropical and subtropical countries of South America, Asia and Africa. Although, there are several factors affecting the success of this method, the effective protocol of bitter melon anther culture has not been developed at present. The results of this study showed that the microspore developmental stage has a significant $(\mathrm{p} \leq 0.05)$ effect on speed and rate of callus formation. It was revealed that the frequency and the rate of callus formation and the morphology of callus substantially depend on the composition and concentration of growth regulators in the nutrient medium. In addition, the dynamics of callus formation in bitter melon anther culture was first studied. The main objective of the work was to study the influence of the microspore developmental stage and the composition of nutrient medium on the ability of callus formation in bitter melon anther culture in vitro. Plants of the $F_{1}$ hybrid bitter melon Diago 26 were grown in field in Dailoc district, Quangnam province (Vietnam) in 2018 according to the standard technique for obtaining commercial fruits. The buds harvested at 5-7 am were stored in plastic bags in dark condition at $4{ }^{\circ} \mathrm{C}$ for 1 day. Before culturing of anther, flower buds were surfaced sterilized using $70 \%$ ethanol and $5 \%$ sodium hypochlorite $(\mathrm{NaOCl})$. Anther removed from flower buds were inoculated in the induction medium in the horizontal laminar air flow; then incubated at $25 \pm 2{ }^{\circ} \mathrm{C}$ and a photoperiod of $16 \mathrm{~h}$ light $/ 8 \mathrm{~h}$ dark for 4 weeks. Three variants of the Murashige-Skoog (MS) nutrient mediums were used, differing in composition and concentration of growth regulators: MK1 with the addition of $1.0 \mathrm{mg} / \mathrm{l} 2.4-\mathrm{D}$ and $1.5 \mathrm{mg} / \mathrm{l} \mathrm{BAP}$; MK2 - 1.5 $\mathrm{mg} / \mathrm{l} 2$ 2,4-D and $1.0 \mathrm{mg} / \mathrm{l} \mathrm{BAP} ; \mathrm{MK} 3-1.5 \mathrm{mg} / \mathrm{l} \mathrm{NAA}, 1.0 \mathrm{mg} / \mathrm{l}$ BAP and $0.5 \mathrm{mg} / \mathrm{l} \mathrm{kinetin.} \mathrm{The}$ completely randomized design with statistical analysis using the software IBM SPSS Statistics Base 22 and Microsoft Excel 2013 were carried out. The cytological analysis result showed that each anther contained microspores with different development stages. Therefore, it is impossible to separate microspores at the unique developmental stage being suitable for anther culture; however, there is always a predominant stage. In this study, buds were divided into two main groups. The first group consisted of buds with the size of $4.0-5.0 \mathrm{~mm}$ with early and mid uninucleate microspores. The second group included buds with the size of 5.1-6.5 mm with late uninucleate and binucleate microspore. After inoculation, the beginning of calli formation was observed within the first week for anther of the buds with the size of 4.0-5.0 mm and within the second week for the buds with the size of 5.1-6.5 mm. The highest frequency of callus formation (93.75 $\pm 2.55 \%$ ) was observed on MS medium supplemented with $1.0 \mathrm{mg} / \mathrm{l}$ of 2,4-D and $1.5 \mathrm{mg} / \mathrm{l}$ of BAP (MK1). Most calli were formed during the second and third week after cultivation. Also, there was the significant difference about the morphology of the calli obtained on three nutrient medium. Calli on medium MK1 were yellow, strongly dense and calli on MS medium with the addition of $1.5 \mathrm{mg} / \mathrm{l}$ of 2,4-D and $1,0 \mathrm{mg} / \mathrm{l}$ of BAP (MK2) being green, strongly dense. Green-yellow, dense calli were obtained on medium supplemented with $1.5 \mathrm{mg} / 1 \mathrm{NAA}$ and $1.0 \mathrm{mg} / 1 \mathrm{BAP}$ and $0.5 \mathrm{mg} / 1$ Kinetin (MK3). However, the effect of the developmental stage of microspores on the morphology of calli was not revealed. Despite receiving a large number of calli, the formation of embryoids was not observed.

Keywords: Momordica charantia L., bitter melon, callus, doubled haploid, anther culture, microspore stage.

\section{REFEREN C ES}

1. Gupta M., Sharma S., Gautam A.K., Bhadauria R. Momordica charantia Linn. (Karala): nature's silent healer. International Journal of Pharmaceutical Sciences Review and Research, 2011, 11(1): 32-37.

2. Ahmad N., Hasan N., Ahmad Z., Zishan M., Zohrameena S. Momordica Charantia: For traditional uses and Pharmacological actions. Journal of Drug Delivery \& Therapeutics, 2016, 6(2): 40-44 (doi: 10.22270/jddt.v6i2.1202).

3. Le M.L., Trieu P.T., Huynh L.A.N. Shoot regeneration from cotyledonary sections of Momordica charantia L. in vitro. Science Journal of Can Tho University, 37(2): 47-54.

4. Reyes R.M. Current status of bitter gourd production and marketing in Asia and market potential of bitter gourd as a functional vegetable. International Bitter Gourd Conference. Hyderadad, India, 2014. Available https://docplayer.net/36306338-Current-status-of-bitter-gourd-production-andmarketing-in-asia-and-market-potential-of-bitter-gourd-as-a-functional-vegetable.html. Accessed February 28, 2019.

5. Arafat S.Y., Nayeem M., Jahan S., Karim Z., Reza H.M., Hossain M.H., Shohel M., Alam M.A. Ellagic acid rich Momordica charantia fruit pulp supplementation prevented oxidative stress, fibrosis and inflammation in liver of alloxan induced diabetic rats. Orient. Pharm. Exp. Med., 2016, 16(4): 267-278 (doi: 10.1007/s13596-016-0242-x).

6. Joseph B., Jini D. Antidiabetic effects of Momordica charantia (bitter melon) and its medicinal potency. Asian Pac. J. Trop. Dis., 2013, 3(2): 93-102 (doi: 10.1016/S2222-1808(13)60052-3).

7. Poolperm S., Jiraungkoorskul W. An update review on the anthelmintic activity of bitter gourd, Momordica charantia. Phcog. Rev., 2017, 11(21): 31-34 (doi: 10.4103/phrev.phrev_52_16).

8. Behera T.K., Behera S., Bharathi L.K., John K.J., Simon P.W., Staub J.E. Bitter gourd: botany, horticulture breeding. Horticultural Reviews, 2010, 37: 101-141 (doi: 10.1002/9780470543672.ch2). 
9. Bal U., Shariatpanahi M.E., Castro A.J., Emery D., Clemente C., Dehestani-Ardakani M., Mozaffari K., Touraev A. Pseudo-embryogenic structures in anther and isolated microspore cultures in vitro: a cautionary guide. Czech J. Genet. Plant Breed., 2012 48(2): 51-60 (doi: 10.17221/176/2011-CJGPB).

10. Monakhos S.G., Nguen M.L., Bezbozhnaya A.V., Monakhos G.F. A relationship between ploidy level and the number of chloroplasts in stomatal guard cells in diploid and amphidiploid Brassica species. Sel'skokhozyaistvennaya Biologiya [Agricultural Biology], 2014, 5: $44-54$ (doi: 10.15389/agrobiology.2014.5.44eng) (in Engl.).

11. Usman M., Bakhsh K., Fatima B., Zaman Q., Shah M.H. Exploring embryogenic competence in anthers of Bitter gourd (Momordica charantia L.) cultivar Faisalabad long. The Journal of Animal \& Plant Sciences, 2015, 25(1): 181-188.

12. Kumar H.G.A., Murthy H.N., Paek K.Y. Embryogenesis and plant regeneration from anther cultures of Cucumis sativus L. Scientia Horticulturae, 2003, 98: 213-222 (doi: 10.1016/S03044238(03)00003-7).

13. Ren J., Wu P., Trampe B., Tian X., Lubberstedt T., Chen S. Novel technologies in doubled haploid line development. Plant Biotechnol. J., 2017, 15(11): 1361-1370 (doi: 10.1111/pbi.12805).

14. Forster B.P., Heberle-Bors E., Kasha K.J., Touraev A. The resurgence of haploids in higher plants. Trends Plant Sci., 2007, 12(8): 368-375 (doi: 10.1016/j.tplants.2007.06.007).

15. Dwivedi S.L., Britt A.B., Tripathi L., Sharma S., Upadhyaya H.D., Ortiz R. Haploids: constraints and opportunities in plant breeding. Biotechnol. Adv., 2015, 33(6): 812-829 (doi: 10.1016/j.biotechadv.2015.07.001).

16. Qiao G., Li H., Liu M., Jiang J., Yin Y., Zhang L., Zhuo R. Callus induction and plant regeneration from anthers of Dendrocalamus latiflorus Munro. In Vitro Cell. Dev. - Pl., 2013, 49(4): 375-385 (doi: 10.1007/s11627-013-9498-8).

17. Pivovarov V.F., Bondareva L.L., Shmykova N.A., Shumilina D.V., Mineikina A.I. New generation hybrids of white cabbage (Brassica oleracea L. convar. capitata var. alba DC) based on doubled haploids. Agricultural Biology, 2017, 52(1): 143-151 (doi: 10.15389/agrobiology.2017.1.143eng) (in Engl.).

18. Tang Y., Li H., Liu J., Liu B., Lio H.P. Callus formation from anther culture in Balsam Pear (Momordica charantia L.). American-Eurasian J. Agric. \& Environ. Sci., 2009, 6(3): 308-312.

19. Tang Y., Liu J., Liu B., Li J., Li X.M., Li H.X. Effect of different treatment on anther callus formation and browning in Balsam pear (Momordica charantia L.). J. Agric. Sci. Technol., 2010, 4(6): 53-56.

20. Tang Y., Liu J., Liu B., Li X.M., Li J., Li H.X. Endogenous hormone concentrations in explant and calluses of Bitter Melon (Momordica charantia L.). Interciencia, 2010, 35(9): 680-683.

21. Pukhal'skii V.A., Solov'ev A.A., Badaeva E.D., Yurtsev V.N. Praktikum po tsitologii $i$ tsitogenetike rastenii [Workshop on plant cytology and cytogenetics]. Moscow, 2007 (in Russ.).

22. Blackmore S., Wortley A.H., Skvarla J.J., Rowley J.R. Pollen wall development in flowering plants. New Phytol., 2017, 174(3): 483-498 (doi: 10.1111/j.1469-8137.2007.02060.x).

23. Dunwell M.J. Haploids in flowering plant: origins and exploitation. Plant Biotechnol. J., 2010, 8: 377-424 (doi: 10.1111/j.1467-7652.2009.00498.x).

24. Germana M.A. Anther culture for haploid and doubled haploid production. Plant Cell Tiss. Org., 2011, 104(3): 283-300 (doi: 10.1007/s11240-010-9852-z).

25. Adhikari P.B., Kang W.H. Association of floral bud and anther size with microspore developmental stage in Campari tomato. Wonye kwahak kisulchi $=$ Korean journal of horticultural science and technology, 2017, 35(5): 608-617 (doi 10.12972/kjhst.20170065).

26. Zhang C., Tsukuni T., Ikeda M., Sato M., Okada H., Ohashi Y., Matsuno H., Yamamoto T., Wada M., Yoshikawa N., Matsumoto S., Li J., Mimida N., Watanabe M., Suzuki A., Komori S. Effects of the microspore development stage and cold pre-treatment of flower buds on embryo induction in apple (Malus $\times$ domestica Borkh.) anther culture. Journal of the Japanese Society for Horticultural Science, 2013, 82(2): 114-124 (doi: 10.2503/jjshs1.82.114).

27. Ibrahim A.M., Kayat F.B., Hussin Z.E.S.M., Susanto D., Ariffulah M. Determination of suitable microspore stage and callus induction from anthers of kenaf (Hibiscus cannabinus L.). The Scientifc World Journal, 2014, 2014: Article ID 284342 (doi: 10.1155/2014/284342).

28. Shmykova N.A., Shumilina D.V., Suprunova T.P. Doubled haploid production in Brassica L. species. Russian Journal of Genetics: Applied Research, 2016, 6(1): 68-77 (doi: 10.1134/S2079059716010123)

29. Gałązka J., Niemirowicz-Szczytt K. Review of research in haploid production in cucumber and other curcubits. Folia Horticulturae, 2013, 25(1): 67-78 (doi: 10.2478/fhort-2013-0008).

30. Kumar H.G.A., Murthy H.N. Effect of sugars and amino acids on androgenesis of Cucumis sativus. Plant Cell Tiss. Org., 2004, 78(3): 201-208 (doi: 10.1023/B:TICU.0000025637.56693.68).

31. Song H., Lou Q., Luo X., Wolukau J.N., Diao W., Qian C., Chen J. Regeneration of doubled haploid plants by androgenesis of cucumber (Cucumis sativus L.). Plant Cell Tiss. Org., 2007, 90: 245-254 (doi: 10.1007/s11240-007-9263-y).

32. Assani A., Bakry F., Kerbellec F., Haicour R., Wenzel G., Foroughi-Wehr B. Production of haploids from anther culture of banana [Musa balbisiana (BB)]. Plant Cell Rep., 2003, 21: 511516 (doi: 10.1007/s00299-002-0557-6). 